\title{
TRIPLE ACTION PALATE EXPANDER
}

\author{
Svetlana Yordanova, Miroslava Yordanova, Stoyan Yovchev \\ Department of Orthodontics, Faculty of Dentistry, Medical University, Plovdiv, \\ Bulgaria
}

\begin{abstract}
Malocclusion correction essentially involves expansion of the maxilla, protrusion of anterior teeth and opening the bite. Expansion is often the stage preceding the treatment with fixed appliances. The elevation of the occlusion using accomplished with different devices (bite planes -fixed or removable, composite material on the occlusall surface of molars) carries the risk of breaking or debonding them.

The present article proposes an expanding appliance with triple action as a therapeutic means of choice in an orthodontic treatment with fixed appliances. The expander can simultaneously be used to protrude upper teeth, to expand the upper jaw and disarticulate the occlusion. It can be easily fabricated in clinical conditions, causes no discomfort and does not hamper oral hygiene because it can be removed and cleaned.
\end{abstract}

Key words: expansion, expanders (fixed and removable), deep bite correction, bite planes

\section{INTRODUCTION}

Correction of complex malocclusions necessarily includes in the treatment plan procedures such as jaw expansion, anterior teeth protrusion and opening the bite. These can be achieved in a mixed dentition by using various functional devices (1). Practice has taught that in a permanent dentition expansion and protrusion most often precede treatment with fixed appliance. Deep bites ( 2) usually do not allow brackets to be bonded on the vestibular surface of lower front teeth if the dental arches have not been disarticulated. There are two solutions of this problem. Most often occlusion is elevated by applying composite material on the occlusal surface of molars. Another approach to the problem could be to fix a bite plane on the lingual surface of the upper central incisors $(3,4,5)$. There are two main disadvantages of these two approaches: debonding and braking of the composit materials or the bite planes, one reason being that patients bite on them.

Use of fixed expanders are associated with another type of disadvantages $(1,6)$. They tends to cause a definitive masticatory, speaking and hygienic discomfort in patients.

Aim: We propose a removable expander with protruding, expanding and disarticulating action and a method for its attachment to the upper jaw.

\section{Design of expander:}

1.Expansion screw and connecting arms (fig.1-1)

2.Expander fixators to the molar bands (fig1-2).

3.Springs for protrusion (fig. 1-3).

4.Orthodontic bands for molars (fig. 1-4).

5.Occlusal coverage of acrylic for premolars and canines (fig.2-1)

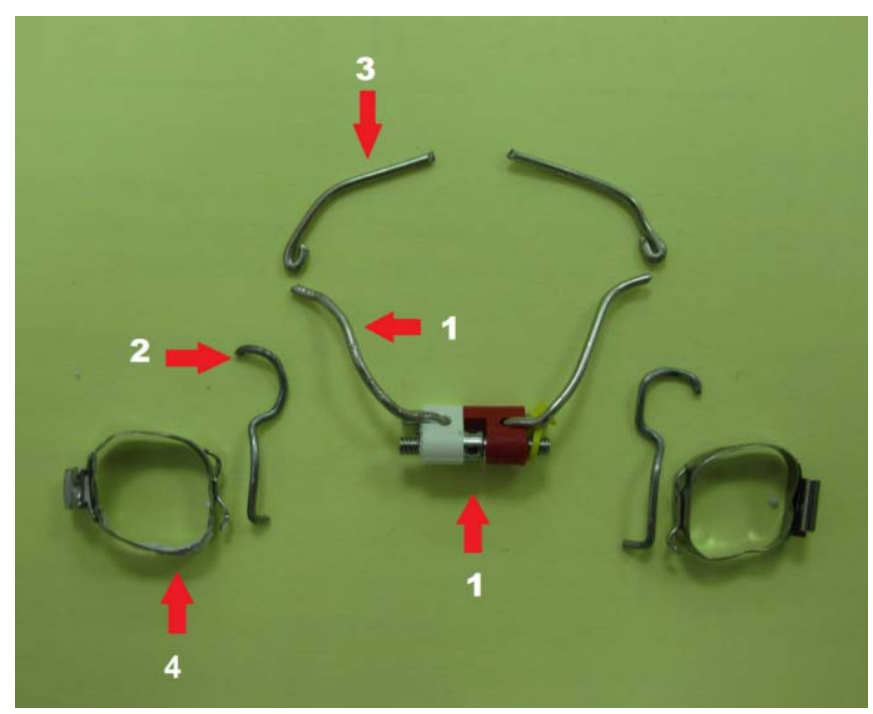

Figure 1. Components of the expander $(1-$ expansion screw and connecting arms; 2 - expander fixators to the molar bands; 3 - protrusion springs; 4- orthodontic molar bands)

\section{Mechanism of action of the expander}

1 . The expanding action of this expander is based on well known biomechanical principles related to the lingual plate effect (7). What makes it particularly convenient for an orthodontist is that the appliance utilises a common, rather than special, expansion screw. The screw expansion action is transmitted to the teeth via the occlusal coverage of acrylic for premolars and canines with the help of the connecting arms (Fig. 2).

2. Elevation and disarticulation is achieved through occlusal coverage of acrylic which extends to half of the occlusal surface of premolars and the lingual surface of canines. The degree of elevation and disarticulation is determined by taking a construction bite. 
The screw is connected to the orthodontic bands through two connecting arms made of $0.9 \mathrm{~mm}$ orthodontic wire (Fig. 2)

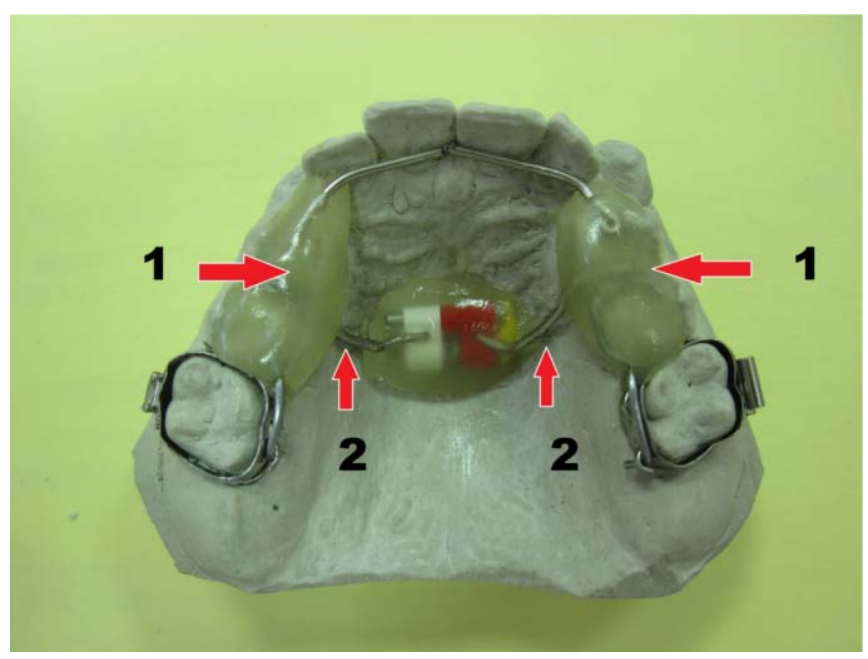

Figure 2. View of the expander $(1-$ occlusal coverage of acrylic for premolars and canines; 2 - connecting arms).

The place of the screw is determined individually by well known methods (7). Isolating and elevating foil of 0.5 $\mathrm{mm}$ is placed between the cast model and the screw to secure the palatal gingiva from traumas during use of the expander (Fig. 3-1).

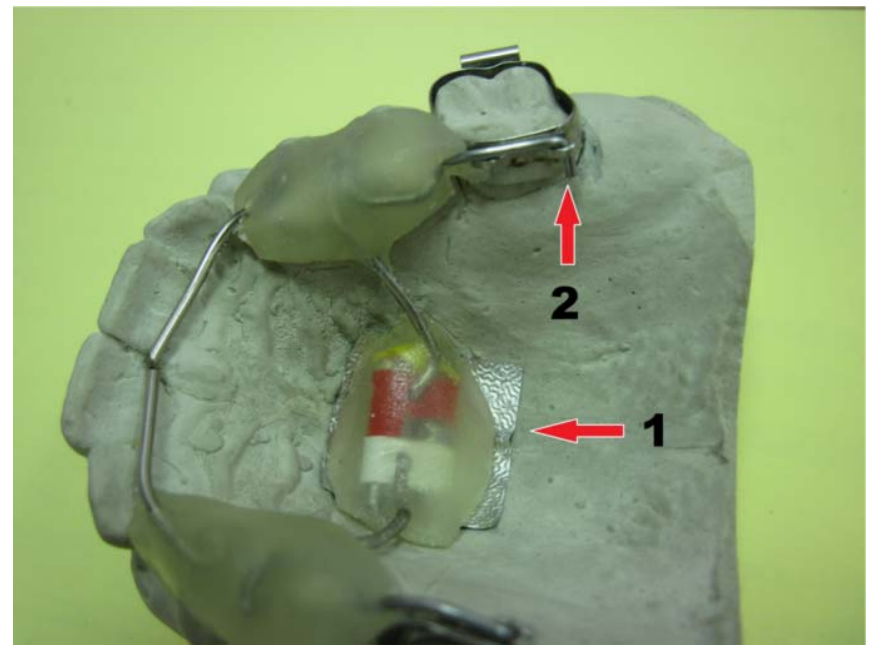

Figure 3. Design of the expander - close view (1 isolating foil; $2-\mathrm{L}$-shaped expander fixators to the molar bands)
3. The protrusion arms are made of orthodontic wire $0.8 \mathrm{~mm}$ in diameter. They pass along the lingual surface of the upper incisors close to the gingival edge. The end of the arms is firmly retained into the occlusal coverage of acrylic.

The expander has two fixators made of orthodontic wire $0.8 \mathrm{~mm}$ in diameter. One of their ends is attached to the plastic bite planes, while the other passes along the lingual wings of the molar bands. The distal end of the fixator in a L-shaped bend is inserted into the distal wing of the molar band. The distal wing is shaped like a hole. The length of the L-shaped arm is adjusted individually but it should not touch the palatal gingiva (Fig. 3).

\section{Fabrication of the expander}

1. Take an impression from the upper jaw together with the adjusted molar bands (not yet bonded).

2. The molar bands are then removed from the teeth and placed into the impression.

3. An impression is taken of the lower jaw and the construction bite is determined. occluder.

4. Plaster models are made and incorporated in an

5. The wire components are manufactured.

6. The screw place is determined and the screw is attached to the model together with the wire elements and the isolating foil by sticky wax.

7. The occlusal coverage of acrylic for premolars and canines and the acrylic covering the screw are shaped in the desired form using photopolymering resin (8).

8 . The expander plastic is polymerised using a photo lamp.

9. The expander is cleaned, polished and adjusted on the model. In the patient's mouth, cement first the molar bands and then adjust the appliance.

\section{CONCLUSIONS}

The proposed expander with triple action has the following advantages:

1. It can simultaneously expand the maxilla, protrude the anterior teeth and disarticulate the bite.

2. It does not cause discomfort.

3. It can be applied along with fixed appliances.

4. It is removable and can be cleaned.

5. It can be fabricated in clinical conditions.

The proposed expander is a method of choice accompanying the orthodontic treatment with fixed aplliances. 


\section{REFERENCES:}

1. Proffit WR, Fields HW Contemporary orthodontics. 1992, 2nd ed. Mosby : 318-341.

2. Nanda R. Correction of deep bite in adults. Dent Clin North Am 1997 Jan;41(1):67-87. [PubMed]

3. Philippe J. Treatment of deep bite with bonded biteplanes. J Clin Orthod 1996 Jul;30(7):396-400. [PubMed]

4. Madsen R. Bonded acrylic lingual biteplanes. J Clin Orthod 1998 May;32(5):311-7. [PubMed]

5. Jackson S, Sandler PJ. Fixed biteplanes for treatment of deep bite. J Clin Orthod 1996 May;30(5):283-7. [PubMed]

6. Graber TM, Vanarsdall RL Jr. Orthodontics current principles and techniques. 1994, 2nd ed. Mosby: 511, 524-531
7. Mutafchiev V. Lingual plate. 1997, Sofia: 53-60, 134.

8. Iordanova $\mathrm{M}$, Iordanova $\mathrm{S}$, Chaprashikyan On. An application of the photopolymerizing plastic materials in the immediate prosthetic treatment. XVIII International scientific conference for young researchers. Sofia, Bulgaria, 2009; S: 232-239.

Address for correspondence:

Dr. Svetlana Yordanova

Department of Orthodontics, Faculty of Dentistry, Medical University, Plovdiv 2, Hristo Botev Str., 4000 Plovdiv, Bulgaria Mobile: 00359878147640, E-mail: svetlaj@gmail.com 